ISSN: 2528-4002 (media online)

ISSN: 2355-892X (print)

Online: http://e-journal.sari-mutiara.ac.id/index.php/KesehatanMasyarakat

DOI: https://doi.org/10.51544/jkmlh.v6i1.1515

\title{
PENGARUH PENDIDIKAN KESEHATAN GIGI TERHADAP PERILAKU MASYARAKAT PENGUNYAH RANUP (SIRIH) DI DESA ANEUK GLEE KECAMATAN INDRAPURI ACEH BESAR
}

\author{
Intan Liana ${ }^{1^{*}}$, Andriani ${ }^{2}$ \\ ${ }^{12}$ Dosen Program Studi Terapi Gigi Jurusan Kesehatan Gigi Poltekkes Kemenkes Aceh \\ Jln. Soekarno Hatta Desa Lagang Kecamatan Lampeunerut Kabupaten Aceh Besar. \\ *Penulis Korespondensi: Intan Liana, Program Studi Terapi Gigi Jurusan Kesehatan \\ Gigi Poltekkes Kemenkes Aceh Jln. Soekarno Hatta Desa Lagang Kecamatan \\ Lampeunerut Kabupaten Aceh Besar..23352 \\ Email : intan_liana62@yahoo.com, Phone : +6281264221974
}

Received: Januari 2021; Accepted: April 2021; Published: Juni 2021

\begin{abstract}
ABSTRAK
Perilaku masyarakat sering kali dipengaruhi oleh kebudayaan atau kebiasaan yang berlaku di masyarakat itu sendiri. Hasil pemeriksaan gigi dan mulut pada 10 orang masyarakat yang mengunyah sirih, menunjukkan $80 \%$ mengalami periodontitis, dengan kondisi sedang dan parah. Penelitian ini bertujuan untuk melihat perbedaan nilai pengetahuan sebelum dan sesudah diberikan intervensi pendidikan kesehatan. Penelitian ini dilakukan di Desa Anuek Glee Kecamatan Indrapuri Aceh Besar. Sampel dari penelitian ini berjumlah 43 orang (total populasi), dengan rancangan penelitian quasi eksperimen dengan desain pre post test only group design. Hasil penelitian Menunjukkan pre test pengetahuan responden pada kategori pengetahuan rendah $(51,1 \%)$, post tes 1 pengetahuan pada kategori tinggi $(90,7 \%)$. pos test ke II, pengetahuan kategori tinggi (76,8\%). pre test sikap pada kategori negatif $(62,7 \%)$, postest 1 pada kategori negatif (55,8\%), post tes II, 76,8\% memiliki sikap yang positif. Pre test tindakan kurang baik (67,4\%), pos tes I 88,4\% menjadi baik, dan setelah post tes Ke II, 86\% tindakan baik. Kesimpulan Ada peningkatan pengetahuan, sikap dan tindakan sebelum dan sesudah diberikan pendidikan kesehatan gigi pada masyarakat pengunyah ranup (sirih) di Desa Aneuk Glee Kecamatan Indrapuri Kabupaten Aceh Besar. Diharapkan kepada perawat gigi dapat melakukan pendekatan pro aktif pada masyarakat yang mengunyah sirih. Dilakukan monitoring kesehatan gigi dan mulut dengan ikut melibatkan pendamping bagi yang berusia lanjut, sehingga dapat mendeteksi dan mencegah risiko penyakit gigi dan mulut sejak dini pada pengunyah sirih.
\end{abstract}

\section{Kata kunci: Pendidikan Kesehatan, Mengunyah Sirih, Perilaku.}

\section{ABSTRACT}

Community behavior is often influenced by the culture or habits prevailing in the community itself. The results of dental and oral examination on 10 people who chewed betel, showed $80 \%$ had periodontitis, with moderate and severe conditions. This study aims to look at differences in the value of knowledge before and after health education interventions are given. This research was conducted in Anuek Glee Village, Indrapuri District, Aceh Besar. The sample of this study amounted to 43 people (total population). The research design is a quasi-experimental design with a pre post test only group design. Analysis using the SPSS program, with $\alpha p<0.05$. Research results indicate the pre-test of respondents' knowledge in the low knowledge category $(51.1 \%)$, post test 1 knowledge in the high category (90.7\%). post test II, high knowledge category (76.8\%). pre test attitude in the negative category (62.7\%), post test 1 in the negative category (55.8\%), post test II, 76.8\% have a positive attitude. Pre-test is not good (67.4\%), post-test I $88.4 \%$ become good, and after post-test II, 86\% of the action is good. Conclusion There was an increase in knowledge, attitudes and actions before and after dental health education was given to the community of betel chewing (betel) in Aneuk Glee Village, Indrapuri District, Aceh Besar District. It is hoped that dental nurses can take a pro-active approach to the community who are chewing betel to provide regular counseling about brushing teeth. Dental and oral health 
ISSN: 2528-4002 (media online)

ISSN: 2355-892X (print)

Online: http://e-journal.sari-mutiara.ac.id/index.php/KesehatanMasyarakat

DOI: https://doi.org/10.51544/jkmlh.v6i1.1515

monitoring is carried out by the health center staff, especially betel chewers by involving assistants for the elderly, so that they can detect and prevent the risk of dental and mouth disease early on in betel chewers.

Keywords: Health Education, Betel Chewing, Behavior.

PENDAHULUAN

Kesehatan gigi dan mulut sangat penting bagi kesehatan setiap individu. Kesehatan gigi dan mulut yang bermasalah atau tidak sehat dapat mengganggu fungsi bicara, pengunyahan, serta fungsi estetika seseorang yang pada akhirnya berdampak pada aktivitas seseorang. Kebiasaan buruk yang dilakukan oleh masyarakat, sangat erat kaitannya dengan terjadinya gangguan pada ginggiva, yang dipengaruhi oleh kebiasaan atau perilaku masyarakat. Perilaku masyarakat sering kali dipengaruhi oleh kebudayaan atau kebiasaan yang berlaku di masyarakat itu sendiri. Masyarakat indonesia sudah sejak lama mengenal perilaku menyirih. Adanya keyakinan masyarakat bahwa dengan mengunyah sirih dapat menguatkan gigi, menyembuhkan luka yang ada dalam rongga mulut, menghilangkan bau mulut, dan lain sebagainya.

Hasil pemeriksaan gigi dan mulut pada 10 orang masyarakat yang mengunyah sirih, menunjukkan $80 \%$ mengalami periodontitis, dengan kondisi sedang dan parah. Masyarakat di desa tersebut memiliki kebiasaan mengunyah sirih, terutama diwaktu senggang, dan malam hari sebelum tidur. Adapun komposisi sirih yang di konsumsi terdiri dari daun sirih, pinang dan kapur. Hampir 90\% dari masyarakat yang di lakukan pemeriksaan tidak menyikat gigi secara teratur, terutama setelah sarapan dan sebelum tidur. Tujuan penelitian ini untuk mengetahui perilaku (pengetahuan, sikap dan tindakan) sebelum dan sesudah diberikan pendidikan kesehatan gigi.

\section{METODE}

Jenis penelitian ini adalah analitik dengan Rancangan penelitiannya adalah quasi eksperimen dengan desain pre post test only group design.

Populasi penelitian ini adalah total populasi masyarakat yang mengunyah sirih berjumlah 43 orang. Intervensi yang dilakukan berupa penyuluhan kesehatan dengan materi terkait upaya pemeliharaan kesehatan gigi dan mulut. Penyuluhan dilakukan dengan metode ceramah, dengan menggunakan media LCD, poster dan demonstrasi dengan media phantom, untuk menjelaskan bagiamana cara menyikat gigi yang baik dan benar. Penyuluhan dilakukan selama 30 menit. Responden juga dibekali dengan booklet dan leaflet, yang dapat dibawa pulang, agar responden dapat mengulang-ulang informasi terkait pemeliharaan kebersihan gigi dan mulut. Analisis hasil penelitian ini menggunakan : uji Paired Samples t-test, yaitu untuk mengetahui perbedaan peningkatan pengetahuan, sikap dan tindakan. Dari pre-test ke post-test I, post-test I ke post-test II dan dari pre-test ke post-test II. Analisis data tersebut menggunakan program Statistik Program for Social Scince (SPSS), dengan pengujian hipotesis berdasarkan taraf signifikan $\mathrm{p}<0.05$.

\section{HASIL}

Berdasarkan hasil penelitian yang telah dilaksanakan dari tanggal 27 Juli sampai dengan 2 Oktober 2019, maka 
Jurnal Kesehatan Masyarakat dan Lingkungan Hidup

Vol. 6 No. 12021

ISSN: 2528-4002 (media online)

ISSN: 2355-892X (print)

Online: http://e-journal.sari-mutiara.ac.id/index.php/KesehatanMasyarakat

DOI: https://doi.org/10.51544/jkmlh.v6i1.1515

diperoleh hasil bahwa mayoritas berumur antara 62 - 67 tahun $(58,1 \%)$ Berdasarkan pendidikan responden mayoritas Sedangkan berdasarkan pekerjaan responden mayoritas Ibu Rumah Tangga berpendidikan SMA yaitu $(62,7 \%)$. yaitu

$(67,4 \%)$.

Tabel 1. Distribusi frekuensi pengetahuan, Sikap dan Tindakan masyarakat tahap pre test, post test I dan post test II

\begin{tabular}{|c|c|c|c|}
\hline \multirow{2}{*}{\multicolumn{2}{|c|}{ Pengetahuan Responden }} & \multicolumn{2}{|c|}{ Hasil penelitian } \\
\hline & & $\mathrm{F}$ & $\%$ \\
\hline \multirow[t]{2}{*}{ Pre test } & 1. Rendah & 22 & 51,1 \\
\hline & 2. Tinggi & 21 & 48,9 \\
\hline \multirow[t]{2}{*}{ Post test 1} & 1. Rendah & 4 & 9,3 \\
\hline & 2. Tinggi & 39 & 90,7 \\
\hline \multirow[t]{2}{*}{ Post tes II } & 1. Rendah & 10 & 23,2 \\
\hline & 2. Tinggi & 34 & 76,8 \\
\hline \multirow{2}{*}{\multicolumn{2}{|c|}{ Sikap Responden }} & \multicolumn{2}{|c|}{ Hasil penelitian } \\
\hline & & $\mathrm{F}$ & $\%$ \\
\hline \multirow[t]{2}{*}{ Pre test } & 1. Negatif & 27 & 62,7 \\
\hline & 2. Positif & 16 & 37,3 \\
\hline \multirow[t]{2}{*}{ Post test 1} & 1. Negatif & 24 & 55,8 \\
\hline & 2. Positif & 20 & 44,2 \\
\hline \multirow[t]{2}{*}{ Post tes II } & 1. Negatif & 10 & 23,3 \\
\hline & 2. Positif & 34 & 76,8 \\
\hline \multirow{2}{*}{\multicolumn{2}{|c|}{ Tindakan Masyarakat }} & \multicolumn{2}{|c|}{ Hasil penelitian } \\
\hline & & $\mathrm{F}$ & $\%$ \\
\hline \multirow[t]{2}{*}{ Pre test } & 1. Kurang Baik & 29 & 67,4 \\
\hline & 2. Baik & 14 & 32,6 \\
\hline \multirow[t]{2}{*}{ Post test 1} & 1. Kurang Baik & 5 & 11,6 \\
\hline & 2. Baik & 38 & 88,4 \\
\hline \multirow[t]{2}{*}{ Post tes II } & 1. Kurang Baik & 6 & 14 \\
\hline & 2. Baik & 37 & 86 \\
\hline
\end{tabular}

Tabel 2. Rerata selisih dan simpangan baku pengetahuan responden

\begin{tabular}{lccc}
\multicolumn{1}{c}{ Data } & Rerata Selisih \pm SD & $\mathrm{t}$ & $\mathrm{P}$ \\
\hline Pre-test ke Post-test I & $17,9 \pm 15,9$ & $-7,35$ & $0,001^{*}$ \\
\hline Post-test I ke Post-test II & $23,2 \pm 16,1$ & 0,94 & $0,051^{*}$ \\
\hline Pre-test ke Post-test II & $15,2 \pm 21,4$ & $-4,14$ & $0,001^{*}$ \\
\hline Ket $: *$ signifikan & & & \\
\hline
\end{tabular}

Tabel diatas Menunjukkan bahwa terjadi peningkatan pengetahuan dari pre-test ke post-test I dengan rerata selisih 17,9 dari post-testI ke post-test II dengan rerata selisih 23,2 dan dari pre-test ke post-testII dengan rerata selisih 15,2. Ada perbedaan rerata nilai pengetahuan yang bermakna secara statistik $(\mathrm{p}<0,05)$.

Tabel 3. Rerata selisih dan simpangan baku sikap responden

\begin{tabular}{cccc} 
Data & Rerata Selisih \pm SD & $\mathrm{t}$ & $\mathrm{P}$ \\
\hline Pre-test ke Post-test I & $30,7 \pm 20,9$ & $-9,63$ & $0,001^{*}$ \\
\hline
\end{tabular}


Jurnal Kesehatan Masyarakat dan Lingkungan Hidup

Vol. 6 No. 12021

ISSN: 2528-4002 (media online)

ISSN: 2355-892X (print)

Online: http://e-journal.sari-mutiara.ac.id/index.php/KesehatanMasyarakat

DOI: https://doi.org/10.51544/jkmlh.v6i1.1515

\begin{tabular}{llll}
\hline $\begin{array}{l}\text { Post-test I ke Post-test } \\
\text { II }\end{array}$ & $3,34 \pm 20,3$ & 1,07 & 0,287 \\
\hline Pre-test ke Post-test II & $27,3 \pm 27,3$ & $-7,73$ & $0,001^{*}$ \\
\hline Ket $:^{*}=$ signifikan & & & \\
\hline
\end{tabular}

Tabel diatas Menunjukkan bahwa terjadi peningkatan sikap anak dari pre-test ke post-test I dengan rerata selisih 30,7 dan signifikant. Namun, dari post-testI ke post-test II dengan rerata selisih 3,3 dan tidak signifikan. Pre -test ke post-testII dengan rerata selisih 27,3. Ada perbedaan rerata nilai sikap yang bermakna secara statistik $(p<0,05)$.

\section{Tabel 4. Rerata selisih dan simpangan baku tindakan responden}

\begin{tabular}{lccc}
\hline \multicolumn{1}{c}{ Data } & Rerata Selisih $\pm \mathrm{SD}$ & $\mathrm{t}$ & $\mathrm{P}$ \\
\hline Pre-test ke Post-test I & $12,5 \pm 16,3$ & $-5,03$ & $0,001^{*}$ \\
\hline Post-test I ke Post-test II & $3,72 \pm 11,1$ & 2,19 & $0,034^{*}$ \\
\hline Pre-test ke Post-test II & $13,2 \pm 15,1$ & $-3,12$ & $0,001^{*}$ \\
\hline Ket $:{ }^{*}=$ signifikan & & & \\
\hline
\end{tabular}

Tabel diatas Menunjukkan bahwa terjadi peningkatan tindakan responden dari pre-test ke post-test I dengan rerata selisih 12,5 dari post-testI ke post-test II dengan rerata selisih 3,72 dan dari pre-test ke post-test II dengan rerata selisih 13,2. Ada perbedaan rerata nilai tindakan yang bermakna secara statistik $(\mathrm{p}<0,05)$

PEMBAHASAN

Berdasarkan hasil penelitian maka terdapat peningkatan rata-rata skor pengetahuan sebelum dan sesudah diberikan perlakuan dengan menggunakan berbagai media saat dilakukan penyuluhan yakni dari 17,1 menjadi 23,2. Ada perbedaan pengetahuan responden sebelum dan sesudah diberikan pendidikan kesehatan $\mathrm{P}=0,001$. Hasil penelitian ini sejalan dengan hasil penelitian Jelita (2014), bahwa terdapat perbedaan skor pengetahuan anak sebelum dan sesudah diberikan penyuluhan kesehatan gigi dan mulut di kelas IV SDN Limboto. Kemampuan seseorang untuk mengingat informasi meningkat lebih tinggi bila ia mempelajari materi dengan metode tertulis (bacaan), karena dengan membaca (bacaan) kemampuan mengingat akan meningkat $72 \%$ sesudah 3 jam (Kaur, 2016). Pendidikan kesehatan dengan media pedoman pemeliharaan kesehatan gigi dan mulut, dilengkapi dengan gambar, sehingga tidak ada rasa bosan saat membaca. Materi yang disampaikan dalam buku pedoman bergambar adalah materi tentang pemeliharaan kesehatan gigi dan mulut pada orang yang mengkonsumsi sirih, cara menggosok gigi dengan benar, dan lain-lain.

Terdapat peningkatan rata-rata skor sikap antara sebelum dan sesudah diberikan pendidikan kesehatan dengan media pre ke post 1 dengan selisih 30,7 p Value 0,001 . Hal ini menunjukkan bahwa ada perbedaan sikap responden sebelum dan sesudah di berikan pendidikan kesehatan. Namun tidak ada perbedaan sikap responden setelah post tes 1 ke post tes ke2 $\mathrm{p}$ value $=0,28$. Karena post 1 ke post es ke 2 jaraknya 3 bulan. Sehingga responden kemungkinan lupa, sebab sikap hanya merupakan respon tertutup dari responden, bukan respon terbuka. Hasil dari pre test ke post test ke II 
Online: http://e-journal.sari-mutiara.ac.id/index.php/KesehatanMasyarakat DOI: https://doi.org/10.51544/jkmlh.v6i1.1515

terdapat perbedaan sikap responden dengan selisih rata-rata 27,3 dan $p$ value 0,001 . Hal ini sejalan dengan penelitian Lubis (2016), bahwa terjadi peeningkatan skor sikap siswa tentang perawatan karies gigi antara sebelum dan sesudah diberikan pendidikan kesehatan dengan metode ceramah di wilayah Puskesmas Wonosegoro II.

Dalam penelitian ini, responden telah mendapat pengetahuan tentang pemeliharaan kebersihan gigi dan mulut, terutama setelah mengkonsumsi sirih dan cara menggosok gigi dengan benar melalui pendidikan kesehatan dengan media buku pedoman, poster dan leaflet. Pengetahuan ini akan membawa responden untuk berpikir dan berusaha supaya tidak mengalami penyakit gigi. Dalam berpikir, komponen emosi dan keyakinan ikut bekerja sehingga responden akan menghindari faktor penyebab penyakit gigi dan rajin menggosok gigi agar terhindar dari penyakit periodontal. Dalam hal ini responden mempunyai sikap tertentu terhadap objek yang berupa pemeliharaan kebersihan gigi dan mulut setelah mengkonsumsi sirih. Selain itu, pendidikan kesehatan dengan media buku pedoman, poster dan leaflet diharapkan mampu meningkatkan pengetahuan responden, sehingga memiliki sikap positif dalam berperilaku sehat.

Terdapat peningkatan rata-rata skor tindakan antara sebelum dan sesudah diberikan perlakuan dengan media buku pedoman pemeliharaan kebersihan gigi dan mulut, dan leafleat. Pada pre test ke post tes 1 selisih rata rata tindakan adalah 12,5 dan $p$ value 0,001 . Post tes 1 ke post test 2 selisih rata rata 3,7 dan $p$ value 0,034 , dan post test 1 ke pos test 2 selisih rata rata 12,2 dengan $\mathrm{p}$ value 0,001 .
Pendidikan kesehatan gigi yang diberikan dengan tehnik demonstrasi, mengajarkan bagiamana cara menggosok gigi yang baik dan benar, ditambah leafleat dan buku pedoman yang menjelaskan secara rinci tehnik menyikat gigi yang benar. Kelebihan leaflet yaitu dari segi produksi hanya membutuhkan waktu yang singkat untuk membuat leaflet dan dari segi biaya tidak membutuhkan banyak biaya.Hal ini sejalan dengan penelitian Luciawaty 2007 (cit Ni Kadek, 2015).

Selama ini ada kepercayaan masyarakat tentang menyirih dapat menghindari penyakit mulut seperti mengobati gigi yang sakit dan nafas yang tidak sedap. Namun masyarakat cenderung kurang memperhatikan efek lain dari menyirih itu sendiri (Hasibuan, 2016). Efek menyirih terhadap gigi dari segi positifnya adalah menghambat proses pembentukan karies, sedangkan efek negatif dari menyirih terhadap gigi dan gingiva dapat menyebabkan timbulnya stein, selain itu dapat menyebabkan penyakit periodontal dan pada mukosa mulut dapat menyebabkan timbulnya lesi-lesi pada mukosa mulut, oral hygine yang buruk, dan dapat menyebabkan atropi pada mukosa lidah (Dondy, 2009). Pada penelitian yang dilakukan di Blitar, Jawa Timur, kebiasaan menyirih tidak lepas dari kepercayaan masyarakat yang mempercayai bahwa mengunyah sirih pinang dapat memberikan kenikmatan seperti orang merokok, sebagai aktifitas di waktu senggang, dapat menghilangkan bau nafas, mengunyah sirih pinang karena turun temurun dan ada yang percaya dapat memperkuat gigi (Ni Kadek, 2015).

Orang yang memiliki perilaku menyirih maka semakin banyak kontak antara jaringan gigi dan penyangganya dengan 
ISSN: 2528-4002 (media online)

ISSN: 2355-892X (print)

Online: http://e-journal.sari-mutiara.ac.id/index.php/KesehatanMasyarakat

DOI: https://doi.org/10.51544/jkmlh.v6i1.1515

bahan-bahan dalam komposisi sugi sirih (quid) misalnya zat kapur yang menyebabkan bertumpuknya kalkulus. Diperparah dengan keadaan masyarakat yang kurang membersihkan giginya seperti menggosok gigi karena kebiasaan menyusur atau menggosokkan segumpalan tembakau pada gigi diyakini sebagai pengganti menggosok gigi. Hal ini sejalan dengan penelitian Sayuti Hasibuan (2016) pada penduduk Tanah Karo Sumatera Utara yang mengindikasikan faktor-faktor yang memiliki hubungan yang bermakna dengan keberadaan lesi-lesi mukosa mulut. Hal ini dimungkinkan akibat semakin lama dan semakin sering seseorang melakukan kebiasaan menyirih maka semakin tinggi resiko untuk terkena lesi-lesi mukosa mulut (Sumerti, 2009).

\section{SIMPULAN}

Berdasarkan hasil penelitian, maka dapat disimpulkan bahwa :

1. Ada peningkatan pengetahuan sebelum dan sesudah diberikan pendidikan kesehatan gigi pada masyarakat pengunyah ranup (sirih) di Desa Aneuk Glee Kecamatan Indrapuri Kabupaten Aceh Besar.

2. Ada peningkatan sikap sebelum dan sesudah diberikan pendidikan kesehatan gigi pada masyarakat pengunyah ranup (sirih) di Desa Aneuk Glee Kecamatan Indrapuri Kabupaten Aceh Besar.

3. Ada peningkatan tindakan sebelum dan sesudah diberikan pendidikan kesehatan gigi pada masyarakat pengunyah ranup (sirih) di Desa Aneuk Glee Kecamatan Indrapuri Kabupaten Aceh Besar.

UCAPAN TERIMAKASIH

Penelitian ini didanai oleh DIPA
Poltekkes Kemenkes Aceh tahun 2019. Penelitian ini dilakukan oleh tim dan dibantu oleh perangkat Desa Aneuk Glee Indrapuri Aceh Besar. Serta terima kasih kepada Direktur Poltekkes Kemenkes Aceh dan seluruh masyarakat yang telah membantu proses penelitian hingga selesai.

\section{REFERENSI}

Dondy,(2009). Kebiasaan Menyirih terhadap Jaringan Periodontal.

Hasibuan S, Aliyah S. (2016), Lesi-lesi mukosa mulut yang dihubungkan dengan kebiasaan menyirih di kalangan penduduk tanah karo, sumatera utara. Dentika Dental Journal.

Jelita F. (2014). Pengaruh Penyuluhan Terhadap Pengetahuan Anak Dalam Memelihara Kesehatan Gigi dan Mulut di Kelas IV SDN 1 Limboto. Jurnal Kesehatan. Vol 2. No 3. Januari 2014.

Kaur, M., dkk. (2016). Effect ofHealth Education on Knowlege,Attitude and ractices About AnaemiaAmong Rural Women in Chandigarh

Lubis F. (2016). Perbedaan Pendidikan Kesehatan Menggunakan Metode Ceramah Dan Audiovisual Terhadap Tingkat Pengetahuan Dan Sikap Perawatan Karies Gigi Anak Di Wilayah Puskesmas Wonosegoro II. Fakultas Ilmu Kesehatan Universitas Muhammadiyah Surakarta.

Ni Kadek Wiwin Parianti, dkk., (2015), Hubungan kebiasaan 
ISSN: 2528-4002 (media online)

ISSN: 2355-892X (print)

Online: http://e-journal.sari-mutiara.ac.id/index.php/KesehatanMasyarakat DOI: https://doi.org/10.51544/jkmlh.v6i1.1515

menyirih terhadap kejadian karies gigi pada lanjut usia di Desa Batubulan Kangin Fakultas Ilmu Kesehatan, Sains Dan Teknologi Universitas Dhyana Pura Bali Jurnal Virgin, Jilid 1,No. 2, Juli 2015, Issn: 2442-2509
Sumerti, N., dkk. (2009). Hubungan Kebiasaan Mengunyah Daun Sirih, Dengan Kesehatan Gigi pada Lansia. Jurnal Skala Husada Edisi Khusus Kesehatan Gigi, Vol. 6: 18-24, Politeknik Kesehatan 